
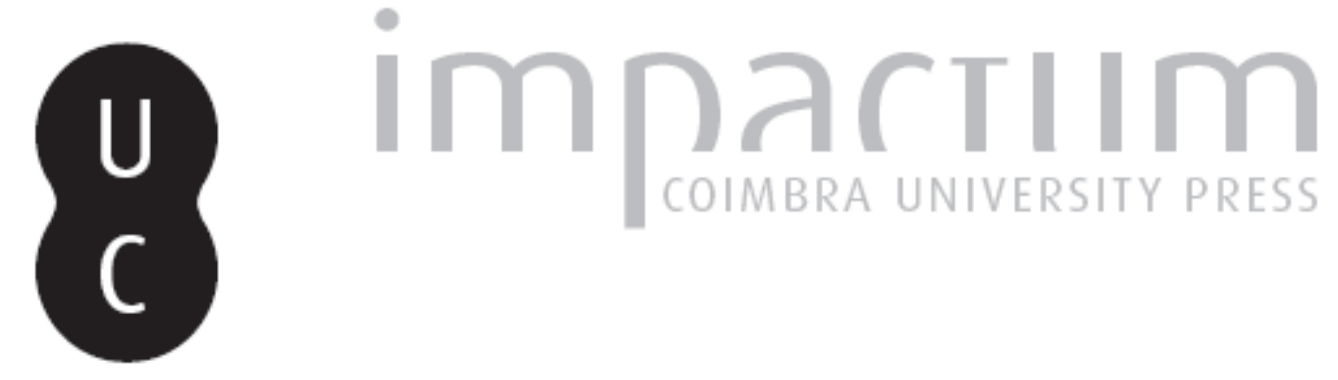

A herança clássica na pintura de Gustave Moreau: o tema de Safo

Autor(es): $\quad$ Ferreira, Luísa de Nazaré

Publicado por: Associação Portuguesa de Estudos Clássicos; Instituto de Estudos

Clássicos

URL

persistente:

URI:http://hdl.handle.net/10316.2/30451

DOI:

DOI:http://dx.doi.org/10.14195/0872-2110_51_15

Accessed : $\quad$ 26-Apr-2023 12:32:44

A navegação consulta e descarregamento dos títulos inseridos nas Bibliotecas Digitais UC Digitalis, UC Pombalina e UC Impactum, pressupõem a aceitação plena e sem reservas dos Termos e Condições de Uso destas Bibliotecas Digitais, disponíveis em https://digitalis.uc.pt/pt-pt/termos.

Conforme exposto nos referidos Termos e Condições de Uso, o descarregamento de títulos de acesso restrito requer uma licença válida de autorização devendo o utilizador aceder ao(s) documento(s) a partir de um endereço de IP da instituição detentora da supramencionada licença.

Ao utilizador é apenas permitido o descarregamento para uso pessoal, pelo que o emprego do(s) título(s) descarregado(s) para outro fim, designadamente comercial, carece de autorização do respetivo autor ou editor da obra.

Na medida em que todas as obras da UC Digitalis se encontram protegidas pelo Código do Direito de Autor e Direitos Conexos e demais legislação aplicável, toda a cópia, parcial ou total, deste documento, nos casos em que é legalmente admitida, deverá conter ou fazer-se acompanhar por este aviso.

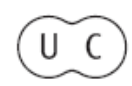




\section{Boletim de}

\section{Estudos Clássicos}

Associação Portuguesa de Estudos Clássicos Instituto de Estudos Clássicos

Coimbra

Junho de 2009 


\section{A Herança Clássica na Pintura de Gustave Moreau O TEMA DE SAFO}

Gustave Moreau nasceu em Paris em 1826 e faleceu nesta cidade em 1898, tendo legado ao Estado Francês a casa em que vivera, com todo o espólio, na condição de que viessem a constituir um museu dedicado à sua obra. O Musée National Gustave Moreau, inaugurado a 14 de Janeiro de 1903, ocupa o $\mathrm{n}^{\circ} 14$ da rua de la Rochefoucauld e acolhe uma grande quantidade de pinturas, aguarelas, desenhos, além dos móveis, livros e objectos que pertenceram ao pintor. A totalidade da sua obra encontra-se dispersa por muitos outros museus e colecções particulares ${ }^{1}$.

A obra extensa e singular de Gustave Moreau é uma referência fundamental na análise da herança clássica na arte ocidental. Filho de Louis Moreau, arquitecto da cidade de Paris e homem de grande cultura, com uma profunda admiração pela Antiguidade clássica, foi incentivado desde cedo a conciliar o talento para as artes visuais com o estudo das Humanidades. Assim, ao longo de uma carreira fecunda que atravessou todo o séc. XIX, Gustave Moreau regressou com frequência a temas inspirados na Bíblia, nos Poemas Homéricos, em Hesíodo e Ovídio, na história antiga e na mitologia. Além desta formação literária, a possibilidade de visitar a Itália e de conhecer de perto os grandes mestres do passado, numa primeira vez quando tinha apenas quinze anos e, mais tarde, numa viagem mais demorada, realizada entre Outubro de 1857 e Setembro de 1859, teria grande significado na definição de uma estética própria. De facto, se inicialmente fora influenciado pelo Romantismo de Eugène Delacroix (1798-1863) e, em especial, do seu amigo Théodore Chassériau (1819-1856), é quando regressa de Itália que Gustave Moreau vai pintar as obras que os especialistas consideram mais originais. Em 1864 apresenta no Salão de Paris o óleo sobre tela que o lançou definitivamente no mundo das artes: Oedipe et le Sphinx, que integra hoje as colecções do Metropolitan Museum of Art de Nova Iorque, valeu-lhe uma medalha de honra e foi adquirido por Jérôme Bonaparte, sobrinho do

1 Vide http://www.artcyclopedia.com/artists/moreau_gustave.html (acedido a 29/05/2009). 
Imperador. Cerca de trinta anos mais tarde, o pintor é nomeado professor da École Nationale des Beaux-Arts de Paris. Entre os seus muitos alunos encontravam-se Henri Matisse e Georges Rouault. Hoje é unanimemente considerado um precursor da estética simbolista.

Nas pinturas de inspiração clássica ocupam lugar de relevo temas da Ilíada (e.g. Aquiles e Briseida, Helena, os amores de Zeus) e da Odisseia (e.g. Polifemo, Circe, as Sereias, os pretendentes de Penélope), a saga dos Argonautas, os trabalhos de Hércules, os mitos de Orfeu, Teseu, Prometeu e Édipo, mas também episódios célebres da história antiga, como o triunfo de Alexandre sobre o rei da Índia. Nas palavras de Geneviève Lacambre (2001: 48), Gustave Moreau "est à la recherche, non pas de sujets nouveaux, mais d'une nouvelle manière de les traiter." Sendo muitas vezes considerado um "pintor-poeta" ou "pintor-pensador", que marcou profundamente os escritores do seu tempo e manteve, ao longo da sua carreira, um diálogo constante entre a pintura e a literatura, merece destaque a série de obras que dedicou à inspiração poética, aos seus cultores mais antigos (Hesíodo, Tirteu e Safo) e aos seus patronos: Apolo e as Musas.

A primeira obra que dedicou a Safo (séc. VII-VI a.C.) foi um desenho feito em 1846, quando tinha vinte anos (Sapho au bord du rocher, colecção particular). A identidade da figura, retratada com um vestuário simples, sem adereços, de expressão melancólica e com os braços pousados sobre os joelhos, é sugerida pelo instrumento de cordas encostado a uma rocha e pelo cenário natural, ao qual alude o título do desenho: a poetisa de Lesbos está sentada na borda de uma falésia e medita, talvez, na decisão que está prestes a tomar.

Gustave Moreau, como muitos outros artistas, poetas e compositores, conhecia a lenda de que Safo se suicidara, atirando-se do rochedo de Lêucade, desesperada por não ser correspondida no amor que sentia por Fáon, um jovem belo de Lesbos. Na Antiguidade, do séc. V ao séc. III a.C., os amores de Safo tornaram-se num tema popular da comédia grega, inspirado decerto por uma interpretação errónea e autobiográfica dos seus versos. A partir do séc. XVI, a lenda do suicídio da poetisa difunde-se na cultura ocidental muito provavelmente por influência das Heróides de Ovídio. Numa obra que reúne as cartas que heroínas célebres teriam dirigido aos seus apaixonados, a $\mathrm{XV}^{\mathrm{a}}$ epístola fictícia é da autoria de Safo, a única figura histórica do conjunto, e foi publicada como apêndice à segunda edição moderna dos seus fragmentos, realizada em 1566 por Henri Estienne (Williamson 1995: 46). 
Desde então, esta imagem de uma mulher desesperada e completamente dominada pelo desejo amoroso ofuscou muitas vezes o reconhecimento da qualidade excepcional da poesia de Safo. No séc. XIX, a paixão por Fáon continuava a inspirar os compositores de música para ópera, como Giovanni Pacini (Saffo, 1840) e Charles Gounod (Sapho, 1851, 1858, 1884), e o salto do rochedo de Lêucade foi tratado por vários pintores franceses, designadamente Antoine-Jean Gros (Sapho à Leucate, 1801) e Théodore Chassériau (Sapho se précipitant dans la mer du rocher de Leucade, 1846; Sapho, 1849).

$\mathrm{O}$ desenho que Gustave Moreau fez em 1846 podia muito bem inspirar-se na parte final da $\mathrm{XV}^{\mathrm{a}}$ epístola das Heróides de Ovídio. Junto de uma fonte, Safo ouve o conselho de uma náiade ('Dirige-te sem demora ao promontório / de Lêucade, e não tenhas medo de saltar do rochedo', Pete protinus altam / Leucada, nec saxo desiluisse time, vv. 171-172). No entanto, quando chega a esse lugar a poetisa hesita ao pensar no amado e, por instantes, parece guardar a esperança de que ele volte (vv. 185-192). O seu lamento dá relevo a um tema que se tornou caro a Gustave Moreau: a perda do dom poético, que em Safo se deveu à extrema dor causada pelo abandono de Fáon (vv. 13-14, 195-206). Parece ser este o aspecto da lenda que mais seduziu o pintor: a mágoa e o desespero da poetisa, não tanto por ter sido abandonada por um amante, mas por já não conseguir compor.

Como era seu hábito, Gustave Moreau voltou mais tarde a Safo, sobretudo a partir de 1866-1867, tendo pintado vários óleos e aguarelas sobre o tema do suicídio. Em todas estas obras, apesar das diferenças, há elementos assíduos, como a lira (que é sempre um instrumento muito elaborado), as aves e o cavalo Pégaso (símbolo da imaginação), os ornamentos e os tons de vermelho da indumentária da poetisa, que se destaca dos tons sombrios dos diferentes cenários. Numa nota de trabalho, o artista escreveu: "Pour ma Sapho, je veux le caractère sacré d'une prêtresse, mais d'une prêtresse poétique. Je combine donc son costume de façon à éveiller dans l'esprit l'idée de la grâce, de la sévérité et avant tout de la variété qui est la plus grande qualité du poète, l'imagination." (apud Mathieu 1994: 99). A ornamentação do vestuário das figuras femininas é, de resto, um traço célebre de Gustave Moreau que, não raramente, introduzia nas suas telas motivos orientais ou exóticos. A exuberância, o colorido e os rasgos de fantasia caracterizaram também os figurinos que em 1883 desenhou para a reposição da ópera Sapho, de Charles Gounod. Considerado extremamente complexo, o guarda-roupa das cinco personagens principais não chegou a ser executado, 
pelo menos como o pintor o imaginara, tendo sido simplificado por Eugène Lacoste, estilista da Ópera de Paris ${ }^{2}$.

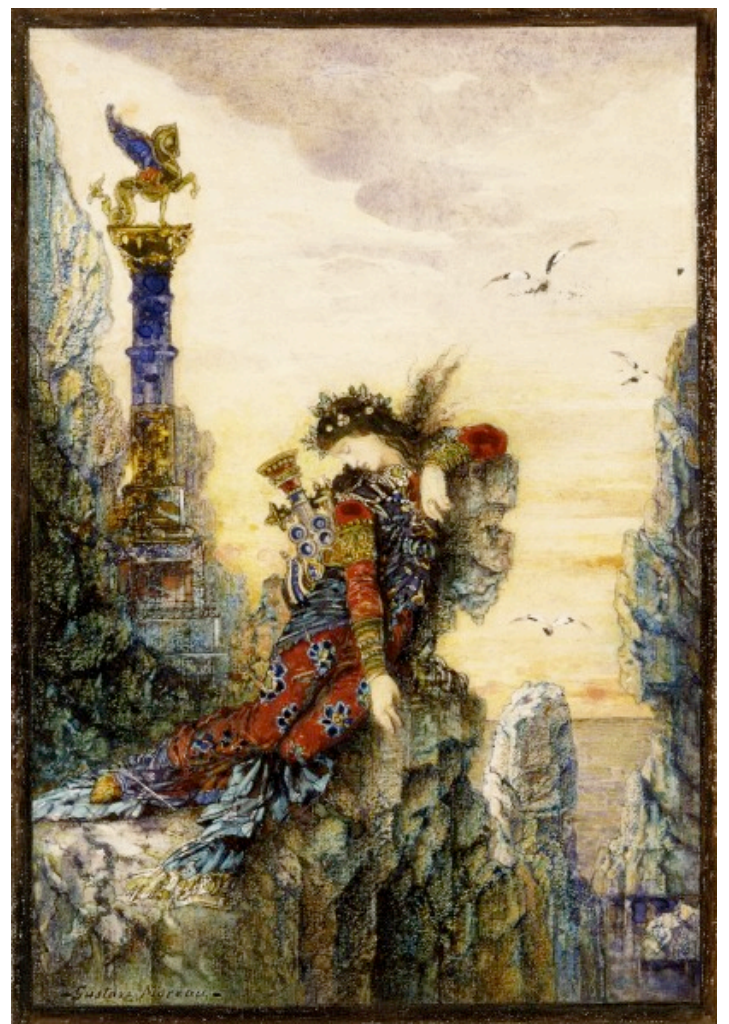

Sapho sur le rocher. 1871-1872. Aguarela. 18,4 cm x 12,4 cm

(C) Victoria and Albert Museum, London.

Uma vez que a datação das obras sobre a poetisa de Lesbos é incerta, não podemos afirmar que a principal evolução temática reside na representação do suicídio. Num período compreendido entre 1867 e 1884, parece evidente que o pintor deu ênfase a três momentos da lenda: Safo, desanimada, no rochedo de Lêucade (e.g. Sapho sur le rocher, 1871-1872,

${ }^{2}$ Cf. Mathieu 1994: 176, 178; Lacambre 1999: 66. 
Victoria and Albert Museum; Sapho au sommet de la roche de Leucade, c. 1872-1876, colecção particular), o salto (e.g. Sapho tombant dans le gouffre, 1867, colecção particular) e a morte da poetisa, à qual dedicou pelo menos três obras, compostas entre 1872 e 1881 . Nestas telas o pintor adoptou o mesmo esquema iconográfico: sobre uma paisagem sombria de pôr-do-sol, a figura resplandecente e colorida de Safo jaz à beira-mar, ornamentada de flores, com a lira e aves brancas junto de si. Não parece estar morta, mas apenas a dormir. Tal como noutras composições, o contraste pictórico põe em destaque, em primeiro plano, o corpo da poetisa, entregue agora a um sono eterno.

Como aconteceu muitas vezes, as imagens de Gustave Moreau inspiraram os escritores contemporâneos. Num poema de vinte estrofes enviado ao pintor em 1885, o poeta Robert Montesquiou evocou a figura de Safo do seguinte modo $^{3}$ :

(...)

Sur les soleils couchants et sous un péristyle,

Des choeurs de Salomés, d'Hélènes, de Saphos

Parmi de grands rayons, luisant comme des feux,

Qu'une lumière d'art sur leur corps clair distille.

(...)

La Sappho morte que le flux ramène au bord

Du flot, comme une fleur à la paroi d'un vase;

Et deux colombes au-dessus de son front mort,

Qui volent, vivant nimbe aux ailes en extase.

(...)

Irresponsable encore Sappho dont la victime

Est sa vie et son coeur, sa lyre et sa vertu;

Que, pour venger l'affront de la défaite intime

La douleur jette aux flots où son chant s'est perdu.

3 Citado em Chaleil 1998: 86-88. O poema, intitulado "Gustave Moreau", foi publicado em Les Paons (Paris, 1908). 


\section{Referências}

Bornecque, H. et Prévost, M. ( $\left.{ }^{5} 2005\right)$, Ovide. Hérö̈des. Paris: Les Belles Lettres.

Chaleil, F. ed. (1998), Gustave Moreau par ses contemporains. Paris: Les Éditions de Paris.

Ferreira, L. N. (2006), "A influência de Safo na música, do séc. XVII aos nossos dias", Humanitas 58: 459-480.

Jacobson, H. (1974), Ovid's Heroides. Princeton, N.J.: Princeton University Press.

Lacambre, G. (1999), Gustave Moreau. Magic and Symbols. New York: Harry N. Abrams, Inc., Publishers.

Lacambre, G. et Leyge, F. (2001), Gustave Moreau et l'Antique. Édition de la Ville de Millau.

Mathieu, P.-L. (1994), Gustave Moreau. Paris: Flammarion.

Mathieu, P.-L. (1998), Gustave Moreau. L'assembleur de rêves. Paris: ACR Édition.

Williamson, M. (1995), Sappho's Immortal Daughters. Cambridge, Mass.: Harvard University Press.

LUÍSA DE NAZARÉ FERREIRA 